\title{
GEL-MAKING SUBSTANCES IN TECHNOLOGY OF MEDICINES
}

\section{Solomenny A. M., Koval A. S.}

\section{INTRODUCTION}

In pharmacy, a relatively new dosage form medicines is gels. Gels combine the properties of solids and liquids and are therefore effective in application. In addition, due to the formation of aqueous internal structures, the gel allows the introduction of chemically incompatible substances, because the water viscous mass prevents the chemical reaction between them.

The composition of the gel in addition to the active pharmaceutical ingredients (AFI) is the need to introduce and auxiliary substances to which include surfactants (surfactants), preservatives, flavors.

Gel is a fairly broad concept that is used to refer to semi-solids with a wide range of characteristics, from almost solid gelatin layers to suspensions of colloidal clays and plastic fatty materials. Gels can be considered as a complex of two interpenetrating phases ${ }^{1}$.

The United States Pharmacopoeia (USP) provides the following definition of gels - semi-solids, which are either suspensions of small size inorganic particles or large organic molecules diluted with liquid. In the first case, inorganic particles (for example, bentonite) form a three-dimensional structure of the card house type in the gel. It is really a two-phase system since inorganic particles are not soluble but only dispersed in the dispersion phase $^{2}$. Large organic molecules form in the solution flexible chains, which twist randomly. These molecules (natural or synthetic polymers) tend to be tangled due to their inherent chaotic motion. Such a system in the macroscopic sense is single-phase, since organic molecules dissolve in the dispersion phase. However, the unique behavior of large molecules in

\footnotetext{
${ }^{1}$ Takamasa Sakai, PhD is Professor in the Department of Bioengineering, Graduate School of Engineering, at The University of Tokyo, Japan, Physics of Polymer Gels. 2020.

Daniel L. Popkin is Assistant Chief of Dermatology, Louis Stokes VA Medical Center and Assistant Professor of Dermatology, University Hospitals, Case Western School of Medicine, Cleveland, OH, USA. He is the Co-Founder of Innova Dermatology, Hendersonville, TN, USA.2019.

${ }^{2}$ Ulrich Schubert, PhD, has been Professor of Inorganic Chemistry at the Institute of Materials Chemistry, Vienna University of Technology, Nicola Hüsing, PhD, was appointed Professor of Materials Chemistry at the Paris-Lodron University of Salzburg, Synthesis of Inorganic Materials, 4th Edition Austria. 2019.
} 
solution causes an increase in viscosity and gel formation, which gave reason to consider such a system at the micro-level as a two-phase, that is, a molecule of colloidal polymer in a solvent. There is an interaction between the organic and inorganic components of the colloidal phase, which causes "structural viscosity" and thickening of the native dispersion phase. Thus, gels have certain characteristics of both liquids and solids ${ }^{3}$.

Polyethylene and its copolymers are used in gel-forming oils. The other two chemical classes are polypeptides (gelatin) and synthetic block copolymers, such as poloxamers. Gels are also classified by the nature of the solvent. Water gels, of course, have a water base. The term "hydrogel" is used to refer to special aqueous gels containing insoluble polymer. In organogels, a non-aqueous solvent is used as the dispersion phase. Examples of organogels are Plastibase (Plastibase - a low molecular weight polyethylene dissolved in a mineral oil with shock cooling) and dispersion of metal stearates in oils ${ }^{4}$.

Solid gels with low solvent concentration are called xerogels. Xerogels are often obtained by evaporation of the solvent, leaving the original gel structure. The gel state can then be restored by the addition of a substance which, upon absorption, causes the gel base to swell. Examples of xerogels are dry gelatin, tragacanth strips, acacia gum, and dry cellulose and polystyrene.

The ideal gel-forming agent for pharmaceutical use should be inert, safe for health and not react with other components of the formula. An example of a potential incompatibility is the combination of a cationic drug, preservative or surfactant with an anionic gel-forming agent. Such a combination results in the deactivation or deposition of a cationic substance. Sodium alginate in solutions reduces the concentration of cationic preservatives, and also forms complexes with chlorpheniramine, which reduces the rate of release of the active substance from the gel dosage form. Polyethylene interacts with phenols and carboxylic acids, which reduces

${ }^{3}$ Takamasa Sakai, PhD is Professor in the Department of Bioengineering, Graduate School of Engineering, at The University of Tokyo, Japan., Physics of Polymer Gels. 2020.

Daniel L. Popkin is Assistant Chief of Dermatology, Louis Stokes VA Medical Center and Assistant Professor of Dermatology, University Hospitals, Case Western School of Medicine, Cleveland, $\mathrm{OH}$, USA. $\mathrm{He}$ is the Co-Founder of Innova Dermatology, Hendersonville, TN, USA.2019.

${ }^{4}$ Ulrich Schubert, PhD, has been Professor of Inorganic Chemistry at the Institute of Materials Chemistry, Vienna University of Technology, Nicola Hüsing, PhD, was appointed Professor of Materials Chemistry at the Paris-Lodron University of Salzburg, Synthesis of Inorganic Materials, 4th Edition Austria. 2019. 
therapeutic efficacy ${ }^{5}$. The addition of a gel-forming agent to the liquid LF should ensure acceptable stability of the semi-rigid structure during the shelf-life, which should not be disturbed by the shear forces that may occur during shaking the bottle, squeezing the contents from the tube or when applied locally. Cost-effectiveness considerations require low concentrations of a gel-forming agent while maintaining the desired product characteristics and properties ${ }^{6}$.

Fluctuations in temperature during normal storage and use should not significantly alter the viscosity of the gel. For example, Plastibaz shows a less pronounced viscosity decrease than petrolatum in the same temperature range. This minimizes unwanted changes to the product properties. Many gels, especially polysaccharide-based ones, are prone to microbial degradation. The introduction of an acceptable preservative can prevent microbial growth and the corresponding deterioration of gel characteristics. They must comply with the intended application. Topical gel preparations should not be sticky. A high concentration of a gel-forming agent or the use of substances with too high a molecular weight may be due to the difficulty of extracting the drug from the package or when applied. In addition, consumers have a preference for gel products with high optical transparency. Therefore, when creating a gel, the task is to get a stable, nice-looking, costeffective drug that is optimally suitable for its intended use ${ }^{7}$.

\section{Swelling}

Gels can absorb moisture and swell, increasing in volume. This usually happens in the first stage of dissolution. The solvent penetrates the gel structure and the gel-gel bonds are converted into gel-solvent bonds. Limited swelling is

${ }^{5}$ Takamasa Sakai, PhD is Professor in the Department of Bioengineering, Graduate School of Engineering, at The University of Tokyo, Japan. Physics of Polymer Gels. 2020.

Vlasenko I. O. Porivnialnyi analiz rynku dermatolohichnykh likarskykh zasobiv v Ukraini za 2013 ta 2018 rr. / I.O. Vlasenko, L.L. Davtian. Zbirnyk naukovykh prats spivrobitnykiv NMAPO im. P.L. Shupyka. 2018. Vyp. 29. S. 194-205.

${ }^{6}$ Daniel L. Popkin is Assistant Chief of Dermatology, Louis Stokes VA Medical Center and Assistant Professor of Dermatology, University Hospitals, Case Western School of Medicine, Cleveland, OH, USA. He is the Co-Founder of Innova Dermatology, Hendersonville, TN, USA. 2019.

Ulrich Schubert, $\mathrm{PhD}$, has been Professor of Inorganic Chemistry at the Institute of Materials Chemistry, Vienna University of Technology, Nicola Hüsing, PhD, was appointed Professor of Materials Chemistry at the Paris-Lodron University of Salzburg, Synthesis of Inorganic Materials, 4th Edition. Austria. 2019

${ }^{7}$ Dr Fiona Lewis, Consultant Dermatologist, St John's Institute of Dermatology and Wexham Park Hospital (Frimley Health Foundation Trust), British Journal of Dermatology, 98, 2, (132-140), (2018) UK.2017 
usually the result of cross-linking in the gel structure, which impedes complete dissolution. Gels swell most often occurs at approximately the same solubility parameters of the solvent and the gel-forming agent.

\section{Syneresis}

Many gel systems have spontaneous volume reductions during prolonged storage. This is due to the displacement of the gel inside the liquid. This process, or syneresis, is inherent not only in organic hydrogels, but also in organogels and inorganic hydrogels. Usually syneresis is more pronounced for low concentrations of polymer. The mechanism of the process of spontaneous reduction in volume is associated with the attenuation of elastic stress during prolonged stay of the gel in the same position. When the voltage is weakened, there is a decrease in the porous space in which the solvent molecules can be located, and this causes the liquid to be squeezed to the surface ${ }^{8}$. Osmotic effects can also act because the $\mathrm{pH}$ and concentration of the electrolytes promote syneresis of the gels, which include ionic gel-forming agents such as gelatin or gum from plantago flea seeds (Plantago afra).

\section{Structure}

Inorganic particles are able to increase the viscosity of the substrate to the state of the gel by forming a structure "card house". Clays such as bentonite or kaolin have a layered structure that intensely absorbs moisture. The flat surface of the bentonite particle has a negative charge and the edge of the charge is positive. Extending the edges to the flat surface of these thin plates in a colloidal solution results in the formation of a three-dimensional mesh of particles that binds the solvent. The forces of interaction between the particles are so weak that they are destroyed by agitation or stirring.

Strong solvents can form long chains of organic gel-forming substances, as is the case in aqueous gels due to the formation of hydrogen bonds between water and the hydroxyl groups of the gelling agent. In weak solvents there is an increased twisting of the molecules of the gel, mainly due to the internal interaction rather than the interaction with the solvent. Each individual segment of dissolved molecules is in constant random motion, colliding with the solvent molecules that also move in the total volume of the liquid. This random motion promotes the interlocking of the

${ }^{8}$ Vlasenko I.O. Porivnialnyi analiz rynku dermatolohichnykh likarskykh zasobiv v Ukraini za 2013 ta 2018 rr. / I.O. Vlasenko, L.L. Davtian. Zbirnyk naukovykh prats spivrobitnykiv NMAPO im. P.L. Shupyka. 2018. Vyp. 29. S. 194-205.

Dr Fiona Lewis, Consultant Dermatologist, St John's Institute of Dermatology and Wexham Park Hospital (Frimley Health Foundation Trust). British Journal of Dermatology. 98, 2, (132-140), (2018) UK.2017 
polymer filaments. Molecularity of molecules causes the corresponding viscosity and structure of organic gels ${ }^{9}$.

Organic polymers used in hydrogels have a tendency to form hydrated water on the shell surface. This, at low concentrations of polymer molecules, causes sliding between the molecules due to the lubricating effect of the shell water molecules. With low hydration, intermolecular attraction forces, such as hydrogen bonds or van der Waals forces, form weak secondary bonds between the polymer filaments. A sufficiently high concentration may form a continuous network of weakly interacting chains. Such an association process can be strong enough to form small local areas of crystalline nature that will be dispersed in a layer of randomly intertwined polymer filaments.

Salts can take away some of the hydrated water of the polymer, which will facilitate the formation of more secondary intermolecular bonds with subsequent solidification and deposition. This phenomenon is known as "subsidence". Polyvalent cations have a strong influence on anionic polymer solutions. The formation of bridges of polymers due to the action of tri- and divalent cations, such as when copper is added to solutions of sodium carboxymethylcellulose or calcium to sodium alginate, causes gel formation ${ }^{10}$.

\section{Alcohols have a similar effect}

However, alcohols affect the characteristics of the solvents and alter the solubility parameters. Adding alcohols often causes coacervation, not gel formation. Coacervation is the separation of a viscous, solvated, highpolymer phase from a solvent-based phase, that is, low polymer content. The effect of temperature depends on the chemistry of the polymer and its mechanism of interaction with the environment. Most gel formulations dissolve better in hot than in cold water. If the temperature is lowered in the presence of a gel in soluble, the degree of hydration decreases and gelation of the whole mass occurs.

${ }^{9}$ Takamasa Sakai, PhD is Professor in the Department of Bioengineering, Graduate School of Engineering, at The University of Tokyo, Japan. Physics of Polymer Gels. 2020.

Daniel L. Popkin is Assistant Chief of Dermatology, Louis Stokes VA Medical Center and Assistant Professor of Dermatology, University Hospitals, Case Western School of Medicine, Cleveland, OH, USA. He is the Co-Founder of Innova Dermatology, Hendersonville, TN, USA.2019.

${ }^{10}$ Ulrich Schubert, PhD, has been Professor of Inorganic Chemistry at the Institute of Materials Chemistry, Vienna University of Technology, Nicola Hüsing, $\mathrm{PhD}$, was appointed Professor of Materials Chemistry at the Paris-Lodron University of Salzburg, Synthesis of Inorganic Materials, 4th Edition. Austria. 2019.

Vlasenko I.O. Porivnialnyi analiz rynku dermatolohichnykh likarskykh zasobiv v Ukraini za 2013 ta 2018 rr. / I.O. Vlasenko, L.L. Davtian. Zbirnyk naukovykh prats spivrobitnykiv NMAPO im. P.L. Shupyka. 2018. Vyp. 29. S. 194-205. 
Some polymers exhibit thermal gelation. These polymers have greater solubility in cold water and solutions of these materials acquire a gel state when heated. Examples of such polymers are methylcellulose and poloxamer. Gelation, which occurs due to hydration and temperature change, usually has the opposite course; with a cyclic change in temperature, the gels become liquid and solidify again. Gelling due to chemical reactions, in particular through crosslinking or salt bridge formation, is irreversible ${ }^{11}$. Therefore, gels obtained by cross-chemical crosslinking are usually unable to be converted to a liquid state by the addition of a solvent or a change in temperature.

An important factor in gel formation is molecular weight. The longer the polymer, the more complex its structure, which causes higher viscosity at the same concentration. Therefore, for the gelation of the solution may be sufficient low concentration of polymer with high molecular weight. But this phenomenon can make it difficult to apply the local gel because of the strong adhesive interaction between the filaments of the gel. Similarly, low molecular weight polymers require greater concentration to increase viscosity and gel formation, which can increase the cost of such agents due to the high content of the gel-forming agent and impair the desired properties of the agent.

\section{Gelling substances}

Numerous polymers are used to obtain the structural grid defining the gel system, including natural resins and gums, cellulose derivatives and carbomers. Although most of these substances exhibit the desired properties in aqueous solutions, there are also polymers forming gel non-polar liquids. Certain colloidal solids exhibit gel-forming action through asymmetric particle flocculation $^{12}$.

${ }^{11}$ Takamasa Sakai, PhD is Professor in the Department of Bioengineering, Graduate School of Engineering, at The University of Tokyo, Japan. Physics of Polymer Gels. 2020.

Daniel L. Popkin is Assistant Chief of Dermatology, Louis Stokes VA Medical Center and Assistant Professor of Dermatology, University Hospitals, Case Western School of Medicine, Cleveland, OH, USA. He is the Co-Founder of Innova Dermatology, Hendersonville, TN, USA. 2019.

${ }^{12}$ Takamasa Sakai, PhD is Professor in the Department of Bioengineering, Graduate School of Engineering, at The University of Tokyo, Japan. Physics of Polymer Gels. 2020.

Daniel L. Popkin is Assistant Chief of Dermatology, Louis Stokes VA Medical Center and Assistant Professor of Dermatology, University Hospitals, Case Western School of Medicine, Cleveland, OH, USA. He is the Co-Founder of Innova Dermatology, Hendersonville, TN, USA. 2019.

Dr Fiona Lewis, Consultant Dermatologist, St John's Institute of Dermatology and Wexham Park Hospital (Frimley Health Foundation Trust), British Journal of Dermatology, 98, 2, (132-140), (2018) UK. 2017. 


\section{Natural polymers}

The use of man-made resins and gums is mentioned in the first historical written sources. Typically, these are branched chain polysaccharides. Most such polysaccharides are anionic (ie, in aqueous solutions or dispersions have a negative charge), although some, such as guar gum, have neutrally charged molecules. The properties of such gums strongly depend on the differences in the quantitative ratio of the sugar elements from which the molecules, their organization and molecular weight are constructed. The chemical structure of natural resins and gums determines their tendency for microbiological destruction and maintenance of microbial growth. Therefore, appropriate preservatives can be added to aqueous systems containing natural gums. As mentioned earlier, cationic antimicrobials are usually not compatible with anionic gums and are practically not used. Although most of the common natural resins and gums are plant extracts and exudates, they also use other sources. Thus, xanthan gum is obtained in a microbiological manner. Many of these gums and resins are derived from natural materials, including cellulose, starch and algin. Some of them are widely used in industry and will be discussed below. The use of natural resins and gums is not necessarily related to the gel-forming properties. Yes, acacia gum (gum arabic) is an effective emulsifier; geranium gum (mainly from Sterculia urens Roxb.) has strong adhesive properties; xanthan g.um is excellent at preventing the deposition of suspensions and emulsions in which the dispersion phase is water. Desirable gel-forming properties of natural resins and gums can be manifested as a result of simple dispersion in water (for example, gum), and as a result of chemical interaction (eg, sodium alginate and calcium). In both cases, the gel is formed by cross-linking that bind some of the polysaccharide molecules, while the rest of these molecules are left in solution free.

\section{Alginates}

These polysaccharides containing D-mannuronic acid and L-guluronic acid in different ratios are obtained from marine brown algae in the form of monovalent or divalent salts. Although other alginate salts are used in industry, sodium alginate has become most widely used. The National Pharmaceutical Directory (NF) provides the following definition of sodium alginate "purified carbohydrate product extracted from marine brown seaweed" and further: "Consists mainly of the sodium salt of alginic acid, polyuric acid and residues of $\beta$-D-manuronic acid, crosslinked the remaining carboxyl group of each block and the aldehyde group is closed with a glycosidic bond".

Gelling is achieved by a decrease in $\mathrm{pH}$ or by reaction with divalent cations. The decrease in $\mathrm{pH}$ is achieved by the conversion of carboxylate ions into free carboxyl groups. This weakens the hydration of the polymer segments and repulsion between them. This requires the presence of a certain 
amount of calcium, usually enough of the small amount already contained in the alginate. At the $\mathrm{pH}$ at which gelation occurs, the calcium in solution is irreversibly bound. Alginates with low residual calcium content acquire a gel form at a $\mathrm{pH}$ below 4 . The maximum static shear stress of the gel is a function of the concentration of alginate; in practice, the minimum value is $0.5 \%$.

In the presence of polyvalent ions, the gel can also be formed at neutral $\mathrm{pH}$. In industry, calcium is most commonly used; Magnesium, oddly enough, is practically not effective. Calcium ions react mainly with the polygluronate segments and form cross-links that crosslink the polymer filaments into a three-dimensional network. The static shear stress of the gel and characteristics such as fragility and propensity for syneresis (displacement of fluid from the gel) are a function of the chemical composition of the alginate, which in turn is determined by the source of origin.

The gel properties and the rate of gel formation depend on the calcium concentration and temperature. Initially, the interaction occurs over the entire surface of the polymer, and at the end of this process, the reaction rate is determined by the diffusion of ions through the surface of the gel. Thus, the formation of gel properties is not a constant process. Subsequently, diffusion continues, calcium ions react with the polymer, and the maximum static shear stress of the gel increases.

Although at a higher concentration of calcium (within acceptable limits) and increases the static static shear stress of the gel, the rate of structural transformations may decrease due to the reduction of the gelation area. This can lead to a heterogeneous gel structure. Low solubility calcium salts or sequestrants are often used to limit the ability of calcium ions to slow down the reaction ${ }^{13}$.

\section{Carrageenin - hydrocolloid extracted}

Carrageenin - hydrocolloid extracted from red seaweed is a mixture of esters of magnesium sulfate, sodium, potassium, ammonium and calcium polymerized galactose and 3,6-anhydrogalactose. The main types of copolymers are capo-, iota- and lambda-carrageenin. Capa and iota fractions form thermally reversible gels in water. This behavior is attributed to the

${ }^{13}$ Ulrich Schubert, PhD, has been Professor of Inorganic Chemistry at the Institute of Materials Chemistry, Vienna University of Technology, Nicola Hüsing, PhD, was appointed Professor of Materials Chemistry at the Paris-Lodron University of Salzburg, Synthesis of Inorganic Materials, 4th Edition Austria. 2019.

Vlasenko I.O., Davtian L.L. Porivnialnyi analiz rynku dermatolohichnykh likarskykh zasobiv v Ukraini za 2013 ta 2018 rr. Zbirnyk naukovykh prats spivrobitnykiv NMAPO im. P. L. Shupyka. 2018. Vyp. 29. S. 194-205.

Dr Fiona Lewis, Consultant Dermatologist, St John's Institute of Dermatology and

Wexham Park Hospital (Frimley Health Foundation Trust), British Journal of Dermatology, 98, 2, (132-140), (2018) UK. 2017. 
temperature-sensitive reorganization of the molecules. At high temperatures, the copolymers exist in the form of random twists, and cooling causes the formation of double helices that act as cross-links.

All carrageenans are anionic substances. Gels with kappa-carrageenin are often brittle, and their maximum static shear stress increases in the presence of potassium ions; iota-carrageenin gels are elastic and retain transparency in the presence of calcium.

\section{Tragakant}

NF cites the following definition of tragacanth "dried gum obtained by the exudation of Astragalus gummifer Labillardiere or other Asian spiny shrubs of the genus Astragalus (Leguminosae family)". These plants are found in the arid mountains of the Middle and Middle East, most of the industrial tragacanth comes from Iran. Tragacanth is a complex substance consisting mainly of acidic polysaccharides (tragacanthic acid) containing calcium, magnesium, potassium and a small amount of neutral polysaccharide of tragacantin. Gum swells in water and a concentration of "high quality" gum $2 \%$ and above causes gel formation. Hydration is long enough, so maximum maximum static shear stress of the gel is reached in a few hours. The rheological properties of tragacanth dispersions are mainly determined by the type of tragacanth used and the processing technology.

Pectin is a polysaccharide extracted from the inner peel of citrus fruits or from apple pomace, used in the manufacture of pharmaceutical jellies and in the food industry. The gel is formed at acidic $\mathrm{pH}$ in aqueous solutions containing calcium and other agents that promote gum dehydration. In the food industry, sugar is used as such agent, which is often added to pectin at the stage of its production. Note that in the pharmaceutical and cosmetic fields, pectin is used without such impurities. Gelling is more intense with a low content of methoxylol in pectin.

\section{Xanthan gum}

Xanthan gum is mainly used as a stabilizer of suspensions and emulsions at concentrations up to $0.5 \%$. Higher concentrations in the aqueous medium ( $1 \%$ and above) form gelling solutions. Xanthan gum is obtained by bacterial fermentation, so its availability and quality are not affected by most of the uncertainties that other natural products are associated with, especially those obtained from plants whose habitat is distributed in politically unstable regions of the world. Thermo-reversible gels are obtained by combinations of xanthan gum and guar gum or carob gum ${ }^{14}$.

${ }^{14}$ Takamasa Sakai, PhD is Professor in the Department of Bioengineering, Graduate School of Engineering, at The University of Tokyo, Japan. Physics of Polymer Gels. 2020. 
Gelan gum is a polysaccharide that is produced by fermentation.

The Food and Drug Administration (FDA) has authorized the use of gum in the food industry. With partial acetylation, the gum forms gels with a thermal reversibility of the hysteresis type. Gels based on raw materials with low acetyl content are more solid, with a consistency similar to gelatin or agar. The static shear stress of the gel is a function of gum concentration and ion content. This gum has a high efficiency, for formation of the gel is not more than $0.05 \%$. Gels are formed only in the presence of free cations. Although both monovalent and divalent ions are suitable for gel formation, divalent ions are required at a much lower concentration, approximately $1 / 25$ of the equivalent concentration of monovalent ions. To form a homogeneous gel, the gum is first dissolved in deionized water heated to a temperature of $70-75^{\circ} \mathrm{C}$. Then the electrolyte (usually calcium salt) is added and the solution is cooled. The gelation temperature is usually in the range from 30 to $45{ }^{\circ} \mathrm{C}$; to dissolve the gel after its solidification requires a higher temperature.

Guar gum is a non-ionic polysaccharide derived from the seeds of guar (nut tree). In aqueous solutions of guar gum, certain polyvalent cations can form crosslinks that convert the solution to gel. The mechanism of this phenomenon is believed to be the formation of chelates between groups of different polymer chains. The disadvantage of such gels is the presence of insoluble plant residues.

Other gums and resins. Chitosan is a natural biopolymer derived from crustacean shells. Chitosan is produced by extraction and partial deacetylation. Unlike most other gums and gums, chitosan has a positive charge (at $\mathrm{pH}$ less than 6.5), which causes it to be attracted to most biological tissues and surfaces that have a negative charge. Various chitosan derivatives have been investigated for various practical applications. Concentrated aqueous chitosan solutions have a gel-like consistency. Interaction with polysaccharides, for example, with alginate, results in the formation of thick gully ${ }^{15}$.

Daniel L. Popkin is Assistant Chief of Dermatology, Louis Stokes VA Medical Center and Assistant Professor of Dermatology, University Hospitals, Case Western School of Medicine, Cleveland, $\mathrm{OH}$, USA. $\mathrm{He}$ is the Co-Founder of Innova Dermatology, Hendersonville, TN, USA. 2019.

Ulrich Schubert, PhD, has been Professor of Inorganic Chemistry at the Institute of Materials Chemistry, Vienna University of Technology, Nicola Hüsing, $\mathrm{PhD}$, was appointed Professor of Materials Chemistry at the Paris-Lodron University of Salzburg, Synthesis of Inorganic Materials, 4th Edition. Austria. 2019.

${ }^{15}$ Takamasa Sakai, PhD is Professor in the Department of Bioengineering, Graduate School of Engineering, at The University of Tokyo, Japan. Physics of Polymer Gels. 2020.

Daniel L. Popkin is Assistant Chief of Dermatology, Louis Stokes VA Medical Center and Assistant Professor of Dermatology, University Hospitals, Case Western School of 


\section{Acrylic polymers}

Carbomer 934P is the official name of one of the representatives of a group of acrylic polymers crosslinked with polyalkenyl ether. The product under the trade name "Carbopol 934P" is used in the pharmaceutical and food industries as a thickener. The suffix "P" means a high-grade polymer that is suitable for use in the manufacture of oral dosage forms. However, carbomer $934 \mathrm{P}$ is also used in most topical preparations. The gel is formed at a concentration of carbomer not lower than $0.5 \%$. In aqueous solution, this polymer, which is available in the form of free acid, is initially uniformly dispersed. After the release of trapped air, the gel is obtained by neutralization with a suitable base. The propagation of negative charge along the polymer chain causes the spiral filaments to unwind and straighten. For the conversion of aqueous solutions to gel, such simple inorganic bases as sodium, ammonium or potassium hydroxide, or basic salts such as sodium carbonate may be used. The $\mathrm{pH}$ should be neutral since the appearance of the gel is adversely affected by both insufficient neutralization and excessively high $\mathrm{pH}$. In cosmetic products sometimes use amines, such as triethanolamine.

Using the organic amine as a neutralizer, it is possible to obtain the gel form of many semi-polar liquids and mixtures of such liquids with water. The compatibility of the polymer with non-aqueous liquids depends on the formation of ion pairs with the amine. Polyols are capable of forming irreversible hydrogen bonds with viscosity-enhancing polymers. The viscosity of the carbomer dispersion decreases in the presence of ions. Thus, at neutral $\mathrm{pH}$, the addition of $1 \%$ sodium chloride causes a decrease in Brookfield viscosity of neutralized carbomer 941 by $1 \%$ by almost $50 \%$ (20 ppm).

Created hydrophobic (poly) acrylic acid derivatives, which are polymeric emulsifiers. This substance is extremely effective and operates at concentrations less than $1 \%$. It is capable of performing the function of the emulsifier both independently and in combination with low-level surfactants. The sensitivity of the polymer to salts causes the destruction of emulsions based on this polymer when applied to the skin, resulting in a fat film on the skin surface. Further contact with water, this film firmly adheres to the skin without back emulsification.

Medicine, Cleveland, OH, USA. He is the Co-Founder of Innova Dermatology, Hendersonville, TN, USA. 2019.

Ulrich Schubert, $\mathrm{PhD}$, has been Professor of Inorganic Chemistry at the Institute of Materials Chemistry, Vienna University of Technology, Nicola Hüsing, PhD, was appointed Professor of Materials Chemistry at the Paris-Lodron University of Salzburg, Synthesis of Inorganic Materials, 4th Edition. Austria. 2019. 
Acrylic resins used in tablet shells are capable of converting polar organic liquids, such as glycerol, polyethylene glycol and low molecular weight polyethylene glycols, to a gel.

\section{Cellulose derivatives}

From cellulose, which is a natural vegetable structural polymer, many useful derivatives have been obtained. Special treatment in the presence of various active substances causes the destruction of the main chains of cellulose and the replacement of certain sites with their hydroxyl parts. The main factors affecting the rheological properties of the final material are the nature of the substituent groups, the degree of substitution, and the average molecular weight of the resulting polymer.

Cellulose derivatives are prone to enzymatic degradation, so they need protection from cellulose sources. To prevent viscosity loss through depolymerization due to the production of enzymes by microorganisms, sterilization of aqueous systems or the addition of appropriate preservatives are used ${ }^{16}$.

Carboxylcellulose, also known as sodium carboxymethylcellulose (CMC), or cellulose gum is an anionic polymer. The industry produces many types of carboxymethyl cellulose, differing in molecular weight and degree of substitution. For gelation to the polymer solution, it is necessary to add an electrolyte with a polyvalent cation, preferably aluminum salts. The characteristics of the gel, in particular the density and elasticity, depend on the concentration of the polymer and the molecular weight. Sequestrants are used to control the availability of free cations and to avoid polymer deposition when the reaction is too fast. Methylcellulose is one of the polymers whose solubility in water decreases with increasing temperature. When heated with an aqueous solution, the viscosity increases markedly to form a gel structure. This process, also called thermal gelation, is a function of the chemical structure of the polymer and depends on additives.

\section{Polyethylene}

Various forms of polyethylene and its copolymers are used to gel hydrophobic liquids. The result is a soft, easily smeared semi-solid that forms a water-resistant film on the surface of the skin. By itself,

${ }^{16}$ Vlasenko I.O. Porivnialnyi analiz rynku dermatolohichnykh likarskykh zasobiv v Ukraini za 2013 ta 2018 rr. / I.O. Vlasenko, L.L. Davtian. Zbirnyk naukovykh prats spivrobitnykiv NMAPO im. P. L. Shupyka. 2018. Vyp. 29. S. 194-205.

Dr Fiona Lewis, Consultant Dermatologist, St John's Institute of Dermatology and Wexham Park Hospital (Frimley Health Foundation Trust), British Journal of Dermatology, 98, 2, (132-140), (2018) UK. 2017. 
polyethylene exhibits gel-forming properties for simple liquid aliphatic carbohydrates, but is incompatible with many other fatty materials for personal hygiene. For this reason, copolymers with vinyl acetate and acrylic acid, which most likely acts as a co-solvent, are used. For gel formation, the polymer is dispersed in heated fat (up to a temperature of more than $80^{\circ} \mathrm{C}$ ) followed by shock cooling to form thin crystals that form a mold matrix.

Microcrystalline silica is able to act as a gel-forming agent for a large number of liquids. The construction of a structural grid is due to the attraction of particles through the action of polar forces, which are mainly hydrogen bonds. Silica has a large surface area (with a small particle size), which results in a high efficiency of building a "fine-grained" structure that encapsulates the liquid. For gelation of nonpolar liquids, a small concentration of microcrystalline silica is sufficient, but competing with the medium for hydrogen bonding in liquids with high polarity weakens the interaction between the particles, so much higher concentrations of silica are required for gelation of such liquids. Glycols can be used to enhance the structure formation process in nonpolar liquids.

\section{Clay}

Montmorillonite clays in water swell due to hydration of exchange cations and electrostatic repulsion of negatively charged forces. At high concentrations, a thixotropic gel is formed in the water, as the particles are combined into a flocculated structure in which some particles are flattened to the edge of other particles by the flat side (the house of cards). Such gels are highly thixotropic and prone to spreading upon agitation. Since electrostatic forces are very important for flocculation, it is not surprising that the rheological properties of clay dispersions are sensitive to salts. Reaction with certain organic molecules can lead to an increase in the hydrophobicity of the surface of the clay particles, which makes the derivative compatible with organic liquids. Adding a well-defined amount of polar additives, such as alcohol, promotes the delamination of small clay flakes, which exacerbates the thickening effect. With insufficient content of polar fluid, it may not be sufficient to separate the clay flakes, and too high a concentration will affect the attraction between the particles.

Microcrystalline cellulose is another solid that can be used as a stabilizer and thickener in water systems. The industry produces products containing hydrophilic polymer (for example, the sodium salt of carboxymethylcellulose), which are intended for use in dispersions of colloidal particles and their protection against electrolytes. The characteristics of the gels based on such solids depend on the method of preparation. In order for the final product to form a widely branched structural grid, very large shear 
forces are usually required for the destruction of the crushed raw material into primary particles (in the case of clay into small flakes).

\section{Surfactants}

Transparent gels are obtained by mixing mineral oil, water and high concentrations (usually $20 \%$ to $40 \%$ ) of certain non-ionic surfactants. Such a combination produces a microemulsion; the presence of the liquid crystalline phase causes the rheology of the semi-solid. Gel characteristics vary depending on the proportion and concentration of the ingredients ${ }^{17}$.

\section{CONCLUSIONS}

According to our research, we have come to the conclusion that the gel properties and the rate of gel formation depend on the concentration of calcium and temperature. Initially, the interaction occurs over the entire surface of the polymer, and at the end of this process, the reaction rate is determined by the diffusion of ions through the surface of the gel. Thus, the formation of gel properties is not a constant process. Subsequently, diffusion continues, calcium ions react with the polymer, and the maximum static shear stress of the gel increases. We also came to the conclusion that the choice of gel-forming substances influences the rheological properties of the gel and the effectiveness of the application of the dosage form.

\section{SUMMARY}

According to the title, the paper describes gel-forming substances in drug technology. In this work, auxiliary substances and their action in creating the basis for medicines are detailed. Much attention is paid to acrylic polymers as they are highly purified, which are suitable for use in the manufacture of oral dosage forms also used in most local preparations. This work is of interest to pharmacists, healthcare professionals.

${ }^{17}$ Takamasa Sakai, PhD is Professor in the Department of Bioengineering, Graduate School of Engineering, at The University of Tokyo, Japan. Physics of Polymer Gels. 2020.

Daniel L. Popkin is Assistant Chief of Dermatology, Louis Stokes VA Medical Center and Assistant Professor of Dermatology, University Hospitals, Case Western School of Medicine, Cleveland, OH, USA. He is the Co-Founder of Innova Dermatology, Hendersonville, TN, USA. 2019.

Ulrich Schubert, $\mathrm{PhD}$, has been Professor of Inorganic Chemistry at the Institute of Materials Chemistry, Vienna University of Technology, Nicola Hüsing, PhD, was appointed Professor of Materials Chemistry at the Paris-Lodron University of Salzburg, Synthesis of Inorganic Materials, 4th Edition Austria. 2019.

Dr Fiona Lewis, Consultant Dermatologist, St John's Institute of Dermatology and Wexham Park Hospital (Frimley Health Foundation Trust), British Journal of Dermatology, 98, 2, (132-140), (2018) UK. 2017 


\section{REFERENCES}

1. Takamasa Sakai, $\mathrm{PhD}$ is Professor in the Department of Bioengineering, Graduate School of Engineering, at The University of Tokyo, Japan. Physics of Polymer Gels. 2020

2. Daniel L. Popkin is Assistant Chief of Dermatology, Louis Stokes VA Medical Center and Assistant Professor of Dermatology, University Hospitals, Case Western School of Medicine, Cleveland, OH, USA. He is the Co-Founder of Innova Dermatology, Hendersonville, TN, USA. 2019

3. Ulrich Schubert, PhD, has been Professor of Inorganic Chemistry at the Institute of Materials Chemistry, Vienna University of Technology, Nicola Hüsing, $\mathrm{PhD}$, was appointed Professor of Materials Chemistry at the Paris-Lodron University of Salzburg, Synthesis of Inorganic Materials, 4th Edition Austria - 2019

4. Vlasenko I.O., Davtian L.L. Porivnialnyi analiz rynku dermatolohichnykh likarskykh zasobiv v Ukraini za 2013 ta 2018 rr. Zbirnyk naukovykh prats spivrobitnykiv NMAPO im. P. L. Shupyka. 2018. Vyp. 29. S. 194-205.

5. Dr Fiona Lewis, Consultant Dermatologist, St John's Institute of Dermatology and Wexham Park Hospital (Frimley Health Foundation Trust), British Journal of Dermatology, 98, 2, (132-140), (2018) UK.2017

Information about authors: Solomenniy A. M., Candidate of Pharmaceutical Sciences, Associate Professor, Ukrainian Military Medical Academy 45/1, Moskovska str., Kyiv, 01015, Ukraine

Koval A. S., Postgraduate Student of the Chair of Pharmaceutical Technology and Biopharmacy Shupyk National Medical Academy of Postgraduate Education 9, Dorogozhyzkaja str., Kyiv, 04112, Ukraine 